\title{
Article \\ Study of Patterns of Movement of Groups of Seed Potatoes in Conical Seed Box Based on the Dem-Model of the Process
}

\author{
Hui Cai ${ }^{1,2}$, Bin $\mathrm{Hu}{ }^{1,2, *}$, Yong Chen ${ }^{1,2,3, *}$, Xin Luo ${ }^{1,2}$, Jian Wang ${ }^{1,2}$, Zibin Mao ${ }^{1,2}$ and Chenglin Yuan ${ }^{1,2}$ \\ 1 College of Mechanical and Electrical Engineering, Shihezi University, Shihezi 832003, China; \\ 20192009024@stu.shzu.edu.cn (H.C.); 1x_mac@shzu.edu.cn (X.L.); 20192009025@stu.shzu.edu.cn (J.W.); \\ 20212309204@stu.shzu.edu.cn (Z.M.); 20202009005@stu.shzu.edu.cn (C.Y.) \\ 2 Northwest Key Laboratory of Agricultural Equipment, Ministry of Agriculture and Rural Affairs of Shihezi \\ University, Shihezi 832003, China \\ 3 College of Mechanical and Electrical Engineering, Henan Agricultural University, Zhengzhou 450002, China \\ * Correspondence: hb_mac@sina.com (B.H.); chenyong@henau.edu.cn (Y.C.)
}

check for updates

Citation: Cai, H.; Hu, B.; Chen, Y.; Luo, X.; Wang, J.; Mao, Z.; Yuan, C. Study of Patterns of Movement of Groups of Seed Potatoes in Conical Seed Box Based on the Dem-Model of the Process. Processes 2022, 10, 363. https://doi.org/10.3390/pr10020363 Academic Editor: Alberto Di Renzo

Received: 9 January 2022

Accepted: 1 February 2022

Published: 14 February 2022

Publisher's Note: MDPI stays neutral with regard to jurisdictional claims in published maps and institutional affiliations.

Copyright: (C) 2022 by the authors. Licensee MDPI, Basel, Switzerland. This article is an open access article distributed under the terms and conditions of the Creative Commons Attribution (CC BY) license (https:// creativecommons.org/licenses/by/ $4.0 /)$.

\begin{abstract}
To reduce the missing rate caused by the arching phenomenon of seed potatoes in the traditional seed boxes of cup-belt potato planters, a conical-shaped seed box comprising a seedmetering box and a reseeding box connected together was proposed. The method in this paper combined the discrete-element-analysis method and response-surface method and took the movement of the seed-potato group in the seed box as the research object. First, by analyzing the force and speed of seed potatoes, the main structural parameters affecting the seed-box seed-metering performance were determined, and the indices for evaluating the seed-box seed-metering performance were established. Additionally, a single-factor simulation test and orthogonal test were carried out for the main structural parameters of the seed box. Using the optimized structural parameters of the seed box, a trial conical seed box was produced, and bench-verification tests were carried out. The results showed that the multiple rate, missing rate and coefficient of the variation of the plant distance for the conical seed box were reduced by $4.76 \%, 4.0 \%$ and $9.18 \%$, respectively. The research results have practical significance as guidance for improving the sowing performance of cup-belt potato planters. At the same time, the research results have reference value for solving the arching problem for granular materials in the box.
\end{abstract}

Keywords: agricultural machinery; discrete-element method; arching phenomenon; seed box; potato planter

\section{Introduction}

At present, seed boxes used in the field of agricultural sowing machinery are designed mostly according to the appropriate structure of the overall machinery. If a seed box with a specific capacity is required, its size can be determined according to the corresponding parameters [1]. It is not difficult to determine that most of the seed boxes are welded (bent) by steel plates, which are generally composed of two parts: the cube in the upper layer and the trapezoidal platform in the lower layer [2-5]. The upper cube is used mainly to increase the capacity of the seed box. If the requirement for the capacity of the seed box is low, the seed box can also be composed of only a trapezoidal platform. However, seeds in such types of seed boxes cannot fall freely, which increases the missing rate for the planter. This article takes the 2CM-2-4 potato planter developed by Huang Yong and others from the School of Mechanical and Electrical Engineering, Shihezi University, Xinjiang, as an example. The seed box is additionally provided with a seed-isolation baffle to divide the seed box into a seed-metering box and a reseeding box to prevent the metering device from damaging the seed potatoes. However, due to the existence of seed-isolation baffles, the cross-sectional shrinkage near the mouth of the reseeding box increases [6]. The seed potato in the reseeding box is supported by the box wall and the mutual extrusion between seed-potato particles, and the friction resistance between particles increases, resulting in 
the formation of a stable arch structure at the discharge port of the reseeding box, causing the inability of the seed potato to fall. This phenomenon is called the seed-potato-arching phenomenon [7]. The arching phenomenon will significantly increase the missing rate for the planter.

To solve the arching problem for granular materials, in terms of taking the arching phenomenon as the research object, Jenike used the flow factor to study the arching of granular material particles in the hopper in the early stage and found that the flow factor is related to the friction angle of material particles and the friction angle in the hopper [8]. In recent years, there have been an extensive number of studies on soil-particle-arch formation $[9,10]$ and track-slab-arch detection [11]. Nikiitenko proposed measures of staticarch stabilization that affected the quality of drainage construction by mathematically simulating the arching of loose materials in the drainage hangar [12]. However, it is rare to study the influence of box structures on particle arches. Europe has standardized the design of the steel-shell structures [13] and announced modern technology and special equipment for potato production [14]. In China, the seed-box structure is designed mostly as the intersection-angle type, according to the empirical design method [15-17]. The arching problem of particles in the box first appears at the intersection angle of the steelplate welding (bending) [18] due to the bad dynamic conditions of particle flow at the intersection angle, the increased resistance and the long-term retention of materials, so the discharge is stopped to form an arching phenomenon [6,19]. Especially in the field of cup-belt potato planters [20], the seed potato is generally cut from the whole potato, and an irregular seed potato aggravates the arch problem in the seed box [21].

In view of the above problems, this paper proposes changing the intersection-angle seed box of cup-belt potato planters into a conical seed box. The movement of the seed potato in the box was numerically simulated using the discrete-element method, and its influence on the structural parameters of the seed box was explored by the movement law of the seed potato to design and optimize the conical seed box. At the same time, the cross section of the seed box changed evenly, and the intersection angle was reduced, which greatly reduced the probability of the arch overlapping of the seed potato in the seed box. The ultimate purpose of this study was to improve the sowing performance of cup-belt potato planters. At the same time, it provides a framework for the study of the arching phenomenon of particle materials in boxes.

\section{Theoretical Analyses}

\subsection{Cross-Angle Seed-Box Seed-Metering Device}

As shown in Figure 1, the seed-metering device mainly includes a seeding-belt assembly, belt-tensioning device, seed cup, seed-cleaning device, seed box and other components [22]. The seed cup is installed on the seeding belt; the drive pulley, the seed-cleaning device and the belt assembly are installed in the seed-belt channel; the belt is tensioned by the tensioning device; and the channel assembly is installed on the seed box to prevent the seed potato from falling from the bottom of the seed box. The seeding belt is driven by the upper belt wheel, and the power is input by the belt transmission. The seeding cup was transferred to the bottom of the seed box along with the seeding belt, and the seed potato was scooped into the seeding cup. The seeding cup carries the seed potato over the driving pulley, and the seed potato falls. The back of the cup is supported, and the seed potatoes are transported under the protection of the back of the seed cup and the seed-belt channel. When the opening of the seed cup and the seed-protection wall reaches a certain angle, the seed potatoes are released on the seed bed to complete the seeding process.

Due to the unreasonable structural design of the seed box, the lower seed potato in the reseeding box is arched, resulting in fewer seed potatoes in the seed-metering box seed. After the seed tuber in the seed-metering box is removed by the seed cup, the seed tuber cannot fill the space position of the removed seed tuber in the seed-metering box in time due to the arch of the seed tuber in the reseeding box, increasing the missing rate for the cup-belt potato planter. If there are many kinds of potatoes in the seed-metering box, there 
is still an arch in the reseeding box, and the seed-taking cup disturbs the potato layer during seed taking. The disturbance can be transmitted to the upper seed potato through the force chain between seed potatoes. The upper seed potato has a great impact on the arch, and the arch collapses under the influence of its own gravity. The collapsed arch forms a local flow or central flow. At this time, a large number of seed potatoes enter the seed-metering box at a high speed, resulting in an increase in the multiple rates of cup-belt potato planters. Moreover, after the arch collapses, a new arch may be formed, resulting in the uneven flow of seed tubers and greatly reducing the seed-metering performance of the seed box.
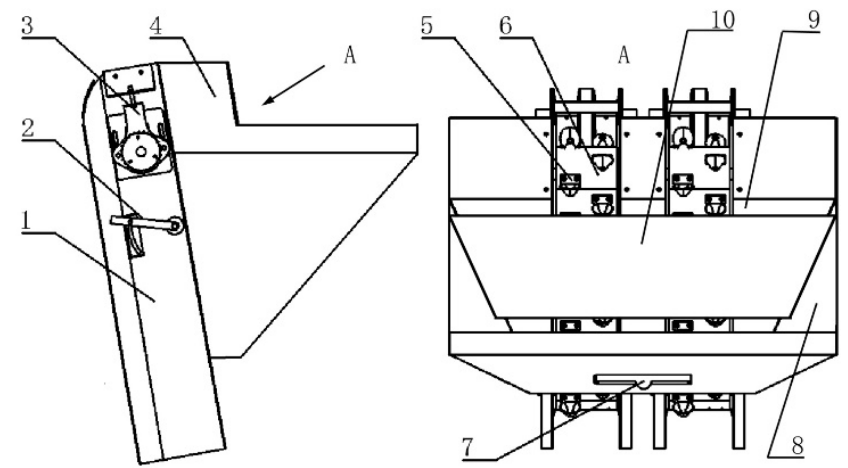

Figure 1. Overall structure of a cup-type potato-metering device: 1 - seed-belt channel; 2 - seed-cleaning device; 3 - seed-belt-tensioning device; 4 - seed box; 5 - seed cup; 6 - seeding belt; 7-discharge port; 8 - seed-metering box; 9 -reseeding box; 10 — seed-isolation baffle.

In Figure 2, the motion state of the seed potato in the intersection-angle seed box is shown. The figure shows that the flow state of the seed potato in the box is extremely unstable. Local arching occurs $1 \mathrm{~s}$ after the simulation, and the central flow occurs $1.5 \mathrm{~s}$ after arching due to the extrusion of the upper seed potato. In the next $2.0 \mathrm{~s}, 2.5 \mathrm{~s}$ and $3.0 \mathrm{~s}$, intermittent unstable flow after the unilateral arch occurs.

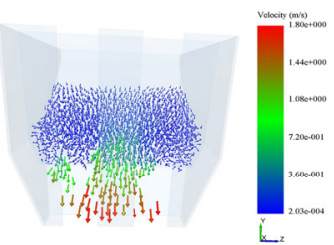

$(1.5 \mathrm{~s})$

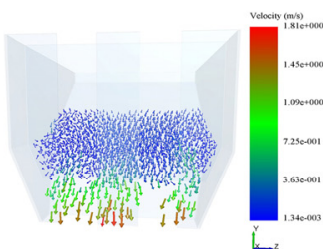

$(2.0 \mathrm{~s})$

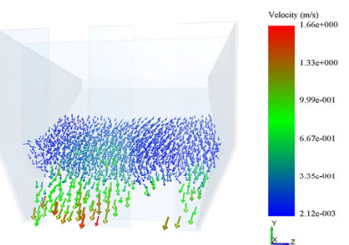

$(2.5 \mathrm{~s})$

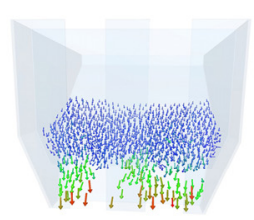

$(3.0 \mathrm{~s})$

Figure 2. The motion state of seed potato in the intersection-angle seed box.

\subsection{Kinetic Analysis of Seed Potato in the Seed Box}

Referring to the particle-flow conditions in the conical silo, if the seed tubers in the seed box are to realize relative movement, the friction resistance $(R)$ between the seed tubers must be overcome $[20,23,24]$ :

$$
R=P f_{1} k c=P f_{1} k \frac{A-A^{\prime}}{A}
$$

where

$P$-the positive pressure existing between the seed potato $(\mathrm{N})$;

$f_{1}$-the friction coefficient between seed potatoes $(\mathrm{N})$;

$k$-the particle shape factor;

$c$ - the cross-sectional shrinkage rate. 
In the reseeding area, the downward movement force, $Q$, of the seed potato can be expressed as:

$$
Q=W_{y}-\int_{0}^{y} P f_{2} n(u / A) d y-\int_{0}^{y} P f_{1} k c d y
$$

where

$W_{y}$ - the gravity of any cross section of the seed box $(\mathrm{N})$;

$\mathrm{P}$-the positive pressure existing between the seed potato $(\mathrm{N})$;

$f_{2}$-the coefficient of the friction between the seed potato and the wall surface of the seed box $(\mathrm{N})$;

$n$-the tilt factor of the seed box;

$u$-the perimeter of the seed-box section (mm);

$A$-the existing cross-sectional area $\left(\mathrm{mm}^{2}\right)$;

$F_{1}$-the coefficient of the friction between the seed potatoes $(\mathrm{N})$;

$k$-the particle-shape factor;

$c$ - the cross-sectional-shrinkage rate.

Among them,

$$
c=\left(A-A^{\prime}\right) / A=8\left(\frac{\operatorname{ctg} \alpha}{1.07+h}-\frac{\operatorname{ctg} \alpha^{2}}{(1.07+h)^{2}}\right)
$$

where

$A$ - the existing cross-sectional area $\left(\mathrm{mm}^{2}\right)$;

$A^{\prime}$ - the cross-sectional area after the descending height $\left(\mathrm{mm}^{2}\right)$;

$\alpha$-the inclination angle of the bottom surface of the seed box $\left(^{\circ}\right)$;

$h$-the reserved height of the seed-isolation baffle $(\mathrm{mm})$.

When a downward flow force $Q>0$ of the seed potato at the cross section of the reseeding box of the mouth of the seed metering is exerted, the seed potato flows downward, and when $Q \leq 0$, the seed potato does not flow and the seed potato arches.

\subsection{Establishment of Test Factors}

\subsubsection{Overall Structure of Conical Seed Box}

The establishment of the structural parameters of the conical seed box: Figure 3 shows a structural diagram of the conical seed box. The seed-box structure is composed mainly of boxes, drainage plates and shunting blocks. The surface of the box divides the seed box into a seed-metering area and a seed-reseeding area. Through the research of Deng Weijian [25] and pre-experimental simulation observations, a drainage plate in the conical seed box was found to be able to reduce the intermittent cutoff and arch state of the seed-potato flow. The shunting block is installed in the seed-filling area to guide the seed potato into the seed-filling area near the seed cup and avoid the seed potato staying in the dead zone of the seed-filling area.

According to the existing structural parameters of the planter, the diameter of the feed inlet of the conical seed box $(D)$ was determined to be $1150 \mathrm{~mm}$, the diameter of the bottom surface of the seed box $(d)$ was $710 \mathrm{~mm},(\theta)$ is the half angle of the top conical portion of the conical seed box, and $(h)$ is the height of the seed box. On this basis, the effects of different structural parameters of the conical seed box on the seed-metering performance of the seed box were studied. When $D$ and $d$ of the conical seed box are determined, $\theta$ is changed and $h$ is changed accordingly. Therefore, $\theta$ and $h$ can be studied according to the same variable. At the same time, the bottom surface of the conical seed box is at a certain angle $(\alpha)$. The inclined bottom surface is obtained after cutting to change the stress state and motion state of the seed potato, make the flow of the seed potato smoother, and reduce the amount of seed potato retained on the bottom surface of the conical seed box. 


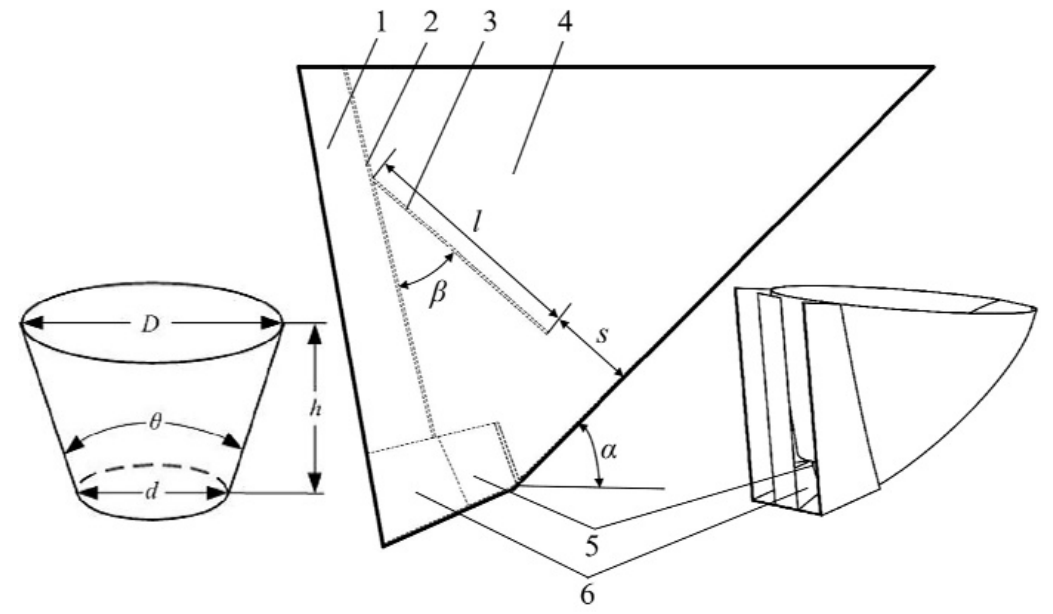

Figure 3. Structure diagram of conical seed box: 1 -seed-metering area; 2 -curved surface of seed box; 3-drainage plate; 4 -reseeding area; 5 -mouth of reseeding area; 6 -shunting block; $\alpha$-inclination angle of the bottom surface of the conical seed box; $\beta$ —inclination angle of the drainage plate; $\theta$-half angle of the top conical portion of the conical-shaped seed box; $l$-the length parameter range of the drainage plate in the seed box; $s$ - the reserved gap of the drainage plate; $h$ - the height of the seed box; $D$-the diameter of the feed inlet of the conical seed box; $d$ - the diameter of the bottom surface of the seed box.

\subsubsection{Parameter (Angle) $\alpha$ Establishment of Parameter Range}

The natural repose angle of $30^{\circ}-32^{\circ}$ for the seed potato [26] was selected in this test. $\alpha$ should be greater than the natural repose angle of the seed potato. The larger the inclination angle, the smaller the support force of the bottom surface of the seed box on the seed potato, and the faster the downward movement speed of the seed potato due to its own gravity, which is more conducive to the seed metering of the seed box. However, the larger $\alpha$ is, the more sharply the capacity of the seed box decreases. After meeting the minimum capacity required by the round-trip travel of the planter, the larger the capacity of the seed box, the better. Therefore, $\alpha$ was selected to be $33^{\circ}, 37^{\circ}, 41^{\circ}, 45^{\circ}$ and $49^{\circ}$ higher than the natural repose angle of the seed potato.

\subsubsection{Parameter (Angle) $\theta$ Establishment of Parameter Range}

In the seed box, an increase in the resistance of the seed potato leads to the arching of the seed potato. A change in the cross-sectional shrinkage of the seed box affects the resistance of the seed potato. $\theta$ is the main factor affecting the cross-sectional shrinkage of the seed box [7]. Therefore, when exploring the influence of seed-box structural parameters on seed-potato movement, $\theta$ is an important parameter in the structural parameters of the seed box.

Since $D$ and $\mathrm{d}$ are fixed values to ensure the capacity of the seed box, the height of the seed box should not be too high, to facilitate manual seed addition. According to preliminary design experience, when $h$ was selected to be $1220 \mathrm{~mm}, 1120 \mathrm{~mm}, 1020 \mathrm{~mm}$, $920 \mathrm{~mm}$, and $820 \mathrm{~mm}$, the structure of the seed box was relatively reasonable. Then, the corresponding $\theta$ values were obtained. They were $21^{\circ}, 24^{\circ}, 27^{\circ}, 30^{\circ}$ and $33^{\circ}$, respectively.

\subsubsection{Establishment of the Length Parameter Range of the Drainage Plate in the Seed Box ( $l$ )}

When exploring the drainage-plate parameters $l$ and the inclination angle of the drainage plate $(\beta)$, the reserved gap (s) between the drainage plate and the bottom of the seed box is the main structural parameter of the drainage plate. When $\beta$ is $35^{\circ}, 40^{\circ}, 45^{\circ}$, $50^{\circ}$ and $55^{\circ}$ for single-factor analysis, with a decrease in $\beta$, the number of intermittent flow cutoffs and arch erections of seed potato were found to be lower. At the same time, $\beta$ should not be too small, and $s$ should not be too large; otherwise, the drainage plate will not function, so $\beta$ was determined to be $55^{\circ}$. s should not be too small; otherwise, when the 
seed potatoes flow, the section shrinkage will become larger, which will lead to serious arch overlapping of the seed potatoes. According to design experience, it is more appropriate to set $s$ at $160 \mathrm{~mm}$. To create a reasonable seed-box structure, $l$ was taken as $350 \mathrm{~mm}, 400 \mathrm{~mm}$, $450 \mathrm{~mm}, 500 \mathrm{~mm}$ and $550 \mathrm{~mm}$ for single-factor simulation-test analysis.

\section{Tests and Methods}

\subsection{Model Establishment and Parameter Setting}

Potatoes are tuber-breeding crops, and cutting seed potatoes can promote oxygen exchange inside and outside the tubers, facilitate early germination, and save potato seeds $[27,28]$. The potato variety Xin Daping was used in the test. Seed potatoes were obtained from $85 \mathrm{~g}$ of whole potatoes cut into two longitudinal pieces weighing approximately $40 \mathrm{~g}$ [20] each. When constructing the seed-potato model, a Vernier caliper was used for surveying and mapping, and the geometric model was established in Solidworks 2019 (Dassault Systemes S.A Ltd., Waltham, MA, USA) based on the surveying and mapping data and then imported into EDEM2018 (DEM Solutions Ltd., Denver, CO, USA) in the step format to perform filling to fit the seed-potato shape (Figure 4a). The mechanical and physical properties of the seed potatoes and seed boxes [29,30] were measured (Table 1).
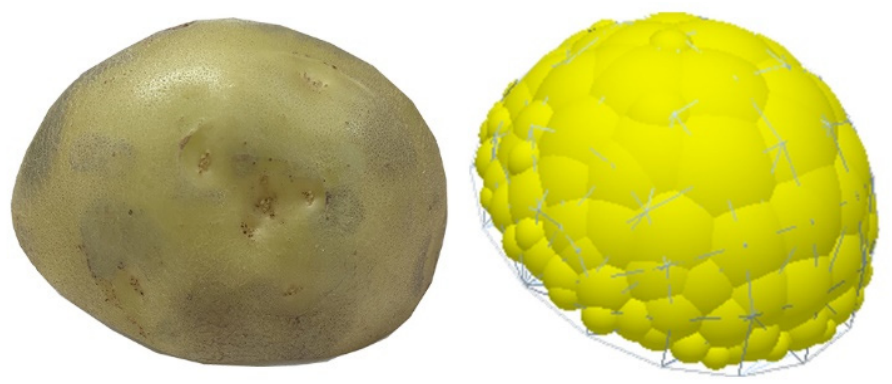

(a)

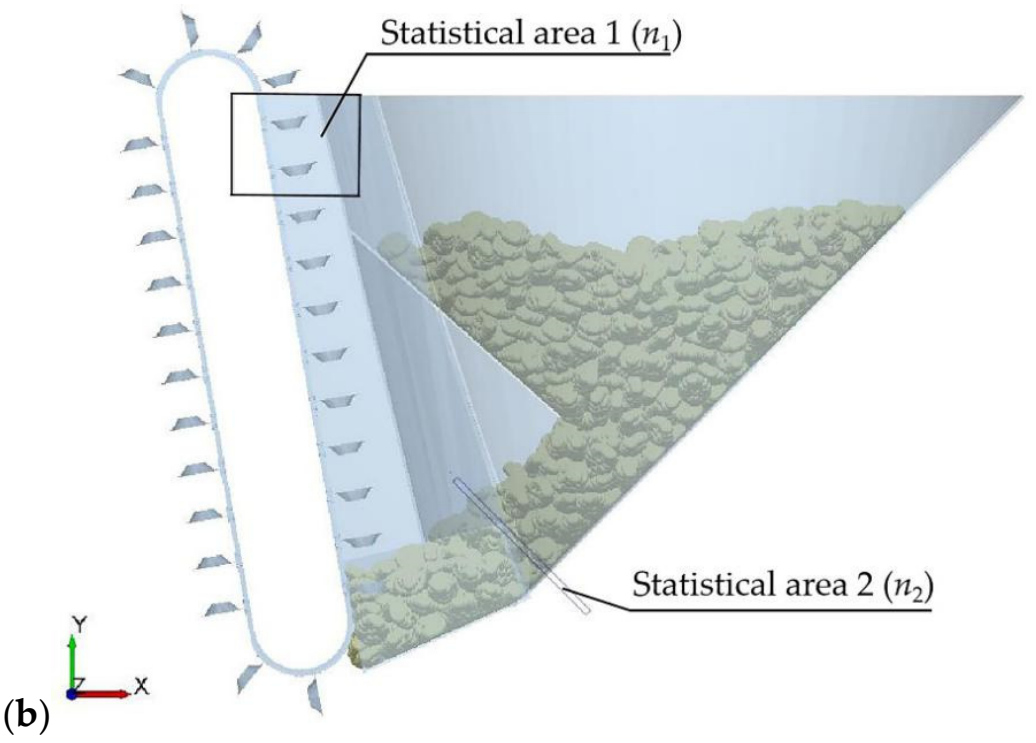

Figure 4. 3D modeling: (a) Particle model of seed potato; (b) 3D model of the seed box and seedmetering mechanism. 
Table 1. Model parameters used in simulations.

\begin{tabular}{|c|c|c|c|}
\hline Material or Contact & Property & Value & Source \\
\hline \multirow{4}{*}{ Seed } & $\begin{array}{c}\text { Dimensions (maximum } \\
\text { diameter } \times \text { thickness) }\left(\mathrm{mm}^{2}\right)\end{array}$ & $\varphi 55 \times 27$ & Measuring \\
\hline & Density $\left(\mathrm{kg} / \mathrm{m}^{3}\right)$ & 1048 & [29] \\
\hline & Shear modulus (Pa) & $1.336 \times 10^{6}$ & [29] \\
\hline & Poisson's ratio & 0.57 & [29] \\
\hline \multirow{3}{*}{ Machine } & Density $\left(\mathrm{kg} / \mathrm{m}^{3}\right)$ & 7800 & $\begin{array}{c}\text { EDEM2018 software } \\
\text { material library }\end{array}$ \\
\hline & Shear modulus (Pa) & $7 \times 10^{10}$ & $\begin{array}{c}\text { EDEM2018 software } \\
\text { material library }\end{array}$ \\
\hline & Poisson's ratio & 0.30 & $\begin{array}{c}\text { EDEM2018 software } \\
\text { material library }\end{array}$ \\
\hline \multirow{3}{*}{ Seed-seed } & Coefficient of restitution & 0.79 & [30] \\
\hline & Dynamic-friction coefficient & 0.452 & [29] \\
\hline & Rolling-friction coefficient & 0.024 & [29] \\
\hline \multirow{3}{*}{ Seed-machine } & Coefficient of restitution & 0.71 & {$[30]$} \\
\hline & Dynamic-friction coefficient & 0.445 & [29] \\
\hline & Rolling-friction coefficient & 0.269 & [29] \\
\hline
\end{tabular}

The 3D-modeling software Solidworks2019 was used to perform 3D modeling of the seed box. This test considered only the uniform flow characteristics of seed potatoes in the seed box and realized the consistency between the number of seed potatoes flowing out of the mouth of the seed-metering area $\left(n_{2}\right)$ and the number of seed potatoes taken by the seed cup of the seed-metering area $\left(n_{1}\right)$. The values were simplified and imported into the EDEM2018 software in step format (Figure 4b).

According to the physical characteristics of the seed-potato-particle surface, the EEPA (Edinburgh Elasto-Plastic Adhesion) model was selected as the simulation contact model [31,32]. To accommodate the geometric size difference of actual seed-potato populations, the particle factory function was applied, and a random distribution was used to randomly generate seed-potato particles. The distribution coefficient was 0.86 to 1.03 times the size of the constructed seed-potato model. A total of 2500 effective seed potatoes with random orientation were generated, and the particles were set. The factory generates particles at a velocity of 5000 particles/s. To reduce the actual use of simulations, the particles were preset to fall freely at $0.5 \mathrm{~m} / \mathrm{s}$. To ensure that the simulation tests were similar to the field operations, after the seed potatoes were in a static state in the reseeding box, the simulation started the operation. Referring to the main technical parameters of the physical prototype, the running velocity of the seed scoop was $0.6 \mathrm{~m} / \mathrm{s}$, the simulation time was $7 \mathrm{~s}$, the test data storage interval was selected as $0.05 \mathrm{~s}$, and the time step was estimated to be $2.30 \times 10^{-4} \mathrm{~s}$ through the EDEM2018 software. In this simulation test, the minimum grid size was set to three times the minimum particle radius $\left(R_{\min }\right)$.

\subsection{Single-Factor Simulation Test and Discussion}

According to the above analysis, combined with the operational requirements of the cup-belt potato planter, the $\alpha, \theta$ and $l$ of the seed box are the influencing factors. To clarify the law of the influence of the structural parameters on the seed-metering performance of the seed box, single-factor simulation tests were carried out.

\subsubsection{Test Evaluation Index}

This study aimed to solve the arching phenomenon in the reseeding box by changing the structural parameters of the seed box and optimizing the uniformity of the reseeding box. Ideally, during the process of filling the seed-metering box, the number of seed potatoes in the seed-metering box should maintain a dynamic balance, and the number of seed potatoes in the seed-metering box should be replenished by the seed potatoes in the reseeding box. Therefore, $C D$ (the amount of seed taken minus $\left(n_{1}\right)$ the amount of seed replenishment $\left(n_{2}\right)$ ) can reflect the reseeding effect of the reseeding box. The smaller 
the absolute value of the compensation difference, the better the reseeding effect of the reseeding box. Second, in this study, $C V$ (the coefficient of the variation of the average seed-population velocity) when the population passed through the reseeding mouth of the reseeding area should reflect the stable filling of the seed box [33,34]. The smaller $C V$ indicates that the phenomenon of the potato group by which the potato initially arches and then collapses is reduced, rendering the intermittent studies less common.

Two statistical areas were established in the EDEM2018 software (Figure 4). Statistical area 1 was set up at the top of the seed-taking belt cup, and the number of seed potatoes in the seed-metering area could be obtained successfully from the seed-taking cup $\left(n_{1}\right)$ during the simulation time. Statistical area 2 was set up at the reseeding mouth, which could obtain the reseeding quantity $\left(n_{2}\right)$ of the reseeding area, the average speed $v$ of the seed-potato group during reseeding in the simulation test and the average downward flow force $(Q)$ of the seed potato passing through the reseeding mouth. In conclusion, the evaluation index of this study can be defined as:

$$
\begin{gathered}
C D=n_{1}-n_{2} \\
C V=\frac{S}{\bar{x}} \times 100 \% \\
S=\sqrt{\frac{\sum_{i=1}^{n}\left(x_{i}-\bar{x}\right)^{2}}{n-1}}
\end{gathered}
$$

where

$C D$ - the compensation difference (grain);

$\mathrm{CV}$ - the coefficient of the variation of the average seed-population velocity (\%);

$n_{1}$ - the number of seed potatoes taken away by the seed cup during the simulation period (grain);

$n_{2}$ - the number of seed potatoes reseeded from the reseeding area to the seed-metering area during the simulation period (grain);

$S$ - the standard deviation of the data set;

$\bar{x}$ - the average value of the data set $(\mathrm{m} / \mathrm{s})$;

$n$-the number of data points in the data set (grains);

$x_{i}$ - the value of a single data point in the data set $(\mathrm{m} / \mathrm{s})$.

\subsubsection{Parameter (Angle) $\alpha$ Single-Factor Simulation Tests and Analysis}

$\theta$ was set to $27^{\circ}$, and $l$ was set to $410 \mathrm{~mm}$. $\alpha$ single-factor simulation tests were carried out at five levels of $33^{\circ}, 37^{\circ}, 41^{\circ}, 45^{\circ}$ and $49^{\circ}$. The relationship between each evaluation index and $\alpha$ was obtained, as shown in Figure 5a. In the seed box with different $\alpha$, the box line diagram and normal curve diagram of $Q$ are shown in Figure 5b. Figure 5a shows that, with increasing $\alpha$, the absolute value of $C D$ gradually decreases because, when $\alpha$ is small, $Q$ is small, the potato layer in the seed-metering area is thin, the missing rate is greater, and fewer seed potatoes are successfully removed, so the absolute value of $C D$ is larger. With increasing $\alpha, Q$ also increases, and the flow speed of the seed potato increases more quickly. When the amount of reseeding increases, the absolute value of $C D$ decreases, and the reseeding effect is better. When $\alpha$ is $49^{\circ}, C D$ is -3 , which indicates that only three seeds are reseeded in the reseeding area at the end of the simulation. Figure 5a shows that $C V$ first decreases rapidly and then increases. When $\alpha$ is small, the seed tubers squeeze each other in the reseeding area, the friction resistance between the seed tubers increases, and there is an arch between the seed tubers. At this time, a small number of seed tubers that do not form an arch fall rapidly, which increases $C V$. When $\alpha$ is $41^{\circ}, C V$ is the smallest, which is $6.89 \%$. Then, with an increase in $\alpha$, the influence of $Q$ on the seed potato is greater than the friction resistance between the seed potatoes. The seed potato flows downward as a whole, the flow velocity is large, and the fluctuation of the velocity gradually increases. 


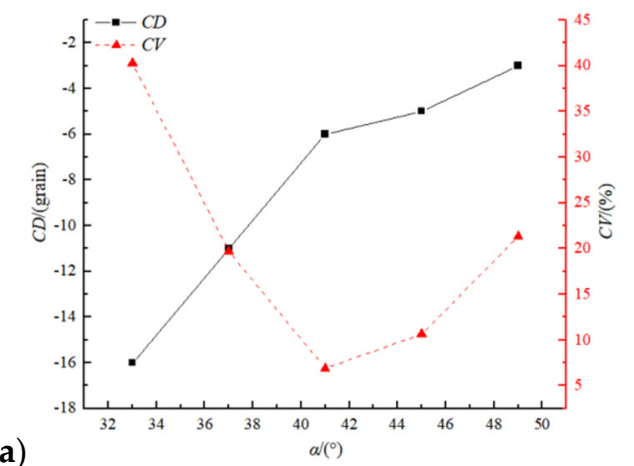

(b)

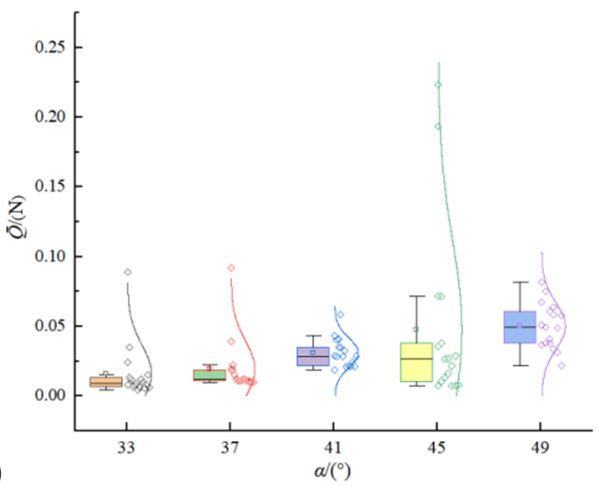

Figure 5. Analysis of the influence of $\alpha$ on the seed-metering performance of the seed box: (a) Relationship between test indices and $\alpha$; (b) Relationship between $Q$ and $\alpha$.

Figure $5 \mathrm{~b}$ shows that changing $\alpha$ has a certain impact on $Q$ on the seed potato; especially, the distribution of the $Q$ value on the seed potato in the whole movement process is obviously improved, indicating that the stability of the seed-potato flow is related to the value of $\alpha$. When $\alpha$ is $45^{\circ}$, the two abnormal values of $Q$ are $0.223 \mathrm{~N}$ and $0.193 \mathrm{~N}$, respectively, and the corresponding times are $3 \mathrm{~s}$ and $4.5 \mathrm{~s}$ after the simulation. The simulation test shows that the reason for the large $Q$ is the sudden and sharp increase in $Q$ caused by the collapse of the potato group after arch bridging during the movement of the seed potato.

\subsubsection{Parameter (Angle) $\theta$ Single-Factor Simulation Tests and Analysis}

$\theta$ is an important structural parameter of the conical seed box that directly affects the stress of the seed potato in the seed box, resulting in the arching phenomenon of the potato group in the seed box. $\alpha$ was set to $41^{\circ}$, and $l$ was set to $450 \mathrm{~mm}$. The $\theta$ values were $21^{\circ}$, $24^{\circ}, 27^{\circ}, 30^{\circ}$ and $33^{\circ}$. The relationship curve between each evaluation index and $\theta$ was obtained, as shown in Figure 6a. With different $\theta$, the box plot plus normal curve of $Q$ is shown in Figure $6 \mathrm{~b}$. As shown in Figure $6 \mathrm{a}$, with increasing $\theta$ (the overall height of the seed box decreases, and the slope of the seed box decreases), $C D$ first decreases and then increases. When $\theta$ is $27^{\circ}$, the minimum $C D$ is three grains, indicating that the better value of $\theta$ is approximately $27^{\circ}$. Figure 6a shows that $C V$ gradually decreases and then increases. When $\theta$ is $30^{\circ}$, the value of $C V$ is the smallest, which is $6.20 \%$, indicating that, when the interaction is not considered, the appropriate $\theta$ is $27^{\circ}-30^{\circ}$.

(a)

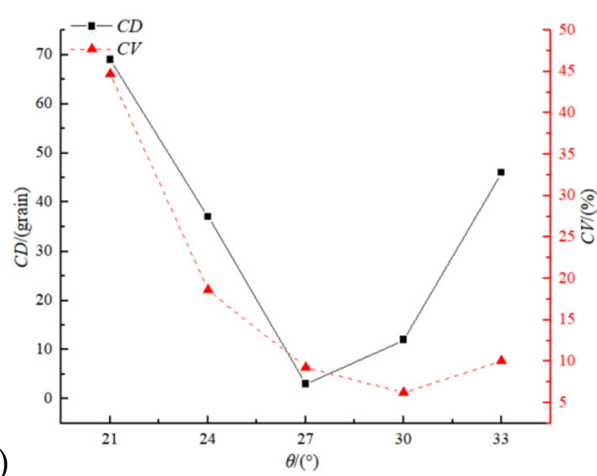

(b)

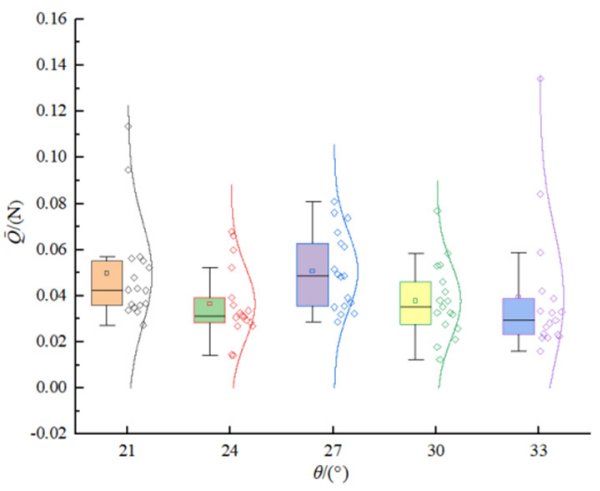

Figure 6. Analysis of the influence of $\theta$ on the seed-metering performance of the seed box: (a) Relationship between test indices and $\theta$; (b) Relationship between $Q$ and $\theta$.

As shown in Figure $6 b$, with increasing $\theta, Q$ gradually decreases. When $\theta$ is $21^{\circ}$ and $33^{\circ}$, the volatility is large, and abnormal values appear. When $\theta$ is $21^{\circ}$, two large abnormal values are $0.095 \mathrm{~N}$ and $0.113 \mathrm{~N}$, respectively, at $6.5 \mathrm{~s}$ and $8.5 \mathrm{~s}$ of the simulation time. The observation of the simulation test shows that, at this time, there is a large degree of overall 
flow in the reseeding area, the number of seed tubers in the seed box decreases, the friction resistance decreases, the seed tubers are greatly affected by their own gravity, and the seed tubers fall rapidly. When $\theta$ is $33^{\circ}$, there are two large abnormal values of $0.084 \mathrm{~N}$ and $0.134 \mathrm{~N}$ at $6 \mathrm{~s}$ and $6.5 \mathrm{~s}$ of the simulation time because of the rapid and unstable flow of seed potatoes after intermittent collapse in the seed box. Considering the requirements of the seed-metering performance of the seed box, the $\theta$ value range should be $24^{\circ}-30^{\circ}$.

\subsubsection{Parameter (Length) $l$ Single-Factor Simulation Tests and Analysis}

$\alpha$ was set to $41^{\circ}$, and $\theta$ was set to $27^{\circ}$. The $l$ values were $350 \mathrm{~mm}, 400 \mathrm{~mm}, 450 \mathrm{~mm}$, $500 \mathrm{~mm}$ and $550 \mathrm{~mm}$, respectively. Single-factor simulation tests were carried out at five levels. The relationship between each evaluation index and $l$ is shown in Figure 7a. The relationship between $l$ and $Q$ is shown in Figure 7b. Figure 7a shows that $C D$ first decreases and then gradually increases with increasing $l$. When $l$ is $450 \mathrm{~mm}$, the absolute value of $C D$ is the smallest, which is one grain. At this time, the seed box is better. $C V$ first decreases rapidly and then increases gradually. When $l$ is $450 \mathrm{~mm}, C V$ is the smallest, which is $12.02 \%$ because, with increasing $l$, the inclination angle of the drainage plate $(\beta)$ remains unchanged, and the installation position of the drainage plate will move upward so that the distance between the bottom end of the drainage plate and the seed-metering area becomes shorter. The more obvious the diversion effect is, the better the diversion effect is. Many seed tubers accumulate in the seed-metering area. There is an intersection between the coefficient of the variation of the supplement and the average population velocity when the length of the deflector is $425-450 \mathrm{~mm}$, and when the length of the deflector is $450 \mathrm{~mm}$, $C D$ and $C V$ have better values at the same time. From the single-factor simulation tests, it is not difficult to see that, when the interaction is not considered, $l$ should be $450 \mathrm{~mm}$.

(a)

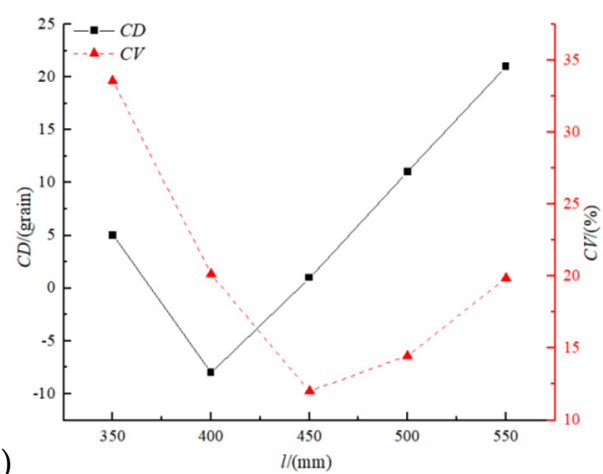

(b)

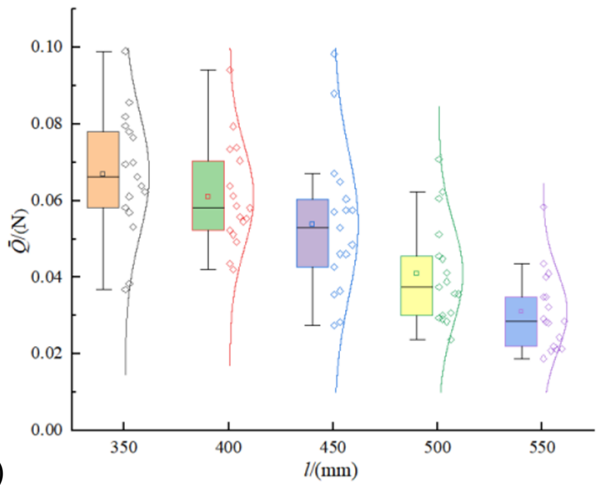

Figure 7. Analysis of the influence of $l$ on the seed-metering performance of the seed box: (a) Relationship between test indices and $l$; (b) Relationship between $Q$ and $l$.

Figure $7 \mathrm{~b}$ shows that ae change in $l$ will cause a large fluctuation, $Q$, in the same seed box, and $Q$ is relatively dispersed, indicating that changing $l$ will have a great impact on the population arch. An extremely obvious rule can be obtained in Figure $7 \mathrm{~b}$. With an increase in $l, Q$ gradually decreases. When $l$ was $350 \mathrm{~mm}, Q$ was $0.067 \mathrm{~N}$; when $l$ increased to $550 \mathrm{~mm}, Q$ decreased to $0.031 \mathrm{~N}$. At this time, the downward flow speed of the potato group was slow, and the seed-potato group easily caused arching in the seed box. Figure 7a shows that the main reason for the increase in $C V$ and the value of $C D$ is that there were different degrees of arching in the reseeding area in various boxes.

\subsection{Orthogonal Simulation Test and Discussion}

\subsubsection{Experimental Design}

From the single-factor test results, the inclination angle of the bottom surface of the conical seed box $(\alpha)$, the half angle of the top conical of the conical seed box $(\theta)$ and the length parameter range of the drainage plate in the conical seed box $(l)$ can be seen to have a significant influence on the test indices for evaluating the conical-seed-box seed-metering 
performance: $C D$ and $C V$. To explore the law of the influence of the above three factors on the seed-metering performance of the seed box and obtain the best combination of structural parameters for the seed box, a three-factor and three-level orthogonal simulation experiment was carried out with $C D$ and $C V$ as the experimental evaluation index [35,36]. According to the analysis results of single-factor tests, $\alpha$ was set to $41^{\circ}, 45^{\circ}$ and $49^{\circ}$; $\theta$ was set to $24^{\circ}, 27^{\circ}$ and $30^{\circ}$; and $l$ was set to $400 \mathrm{~mm}, 450 \mathrm{~mm}$ and $500 \mathrm{~mm}$. The factor-level coding table is shown in Table 2.

Table 2. Horizontal coding table of the simulation test factors.

\begin{tabular}{cccc}
\hline & & Factors ${ }^{\mathbf{1}}$ \\
\cline { 2 - 4 } & $\boldsymbol{X}_{\mathbf{1}}$ & $\boldsymbol{X}_{\mathbf{2}}$ & $\boldsymbol{X}_{\mathbf{3}}$ \\
\hline Level & $\left(\boldsymbol{\alpha}{ }^{\circ}\right)$ & $\left(\boldsymbol{\theta}^{\circ}{ }^{\circ}\right.$ & $(\boldsymbol{l}, \mathbf{m m})$ \\
\hline 1 & 41 & 24 & 400 \\
0 & 45 & 27 & 450 \\
-1 & 49 & 30 & 500 \\
\hline
\end{tabular}

${ }^{1} \alpha$-inclination angle of the bottom surface of the conical seed box, $\theta$-half angle of the top conical of the conical seed box, and $l$-length parameter range of drainage plate in conical seed box.

\subsubsection{Test Results and Discussion}

The numerical-simulation test results are shown in Table 3. The test results were analyzed by using the Design-Expert v8.0.6 (Stat-Ease Ltd., Minneapolis, MN, USA) software to obtain the quadratic-regression models $C D\left(Y_{1}\right)$ and $C V\left(Y_{2}\right)$ :

$$
\left\{\begin{array}{l}
Y_{1}=1.8-10.5 X_{1}-8.7 X_{2}+9.13 X_{3}+4 X_{1} X_{2}-9 X_{1} X_{3} \\
+12.75 X_{2} X_{3}-0.78 X_{1}^{2}+20.98 X_{2}^{2}+4.48 X_{3}^{2} \\
Y_{2}=11.18+7.13 X_{1}-7.44 X_{2}-4.11 X_{3}+1.28 X_{1} X_{2} \\
-6.62 X_{1} X_{3}-0.51 X_{2} X_{3}+5.59 X_{1}^{2}+4.47 X_{2}^{2}+2.27 X_{3}^{2}
\end{array}\right.
$$

where

$X_{1}$-the coding horizontal value of the inclination angle of the bottom surface of the conical seed box $\left(^{\circ}\right)$;

$X_{2}$-the coded value of the half angle of the top conical of the conical seed box $\left(^{\circ}\right)$;

$X_{3}$-the coded value of the length parameter range of the drainage plate in the conical seed box (mm).

Analysis of variance and significance testing of the regression coefficient were carried out for the above quadratic-regression model. Table 4 shows that the $C D$ regression Model $p<0.01$ shows that the $C D$ quadratic-regression model is extremely significant; the lack of fit $p>0.05$, and the lack of fit is not significant, indicating that the quadratic-regression equation fitted by the model is consistent with the numerical-simulation test results, and can correctly reflect the relationship between $Y_{1}$ and $X_{1}, X_{2}$ and $X_{3}$. The regression model can better predict various test results in the optimization test. Among these test results, the primary terms $X_{1}(\alpha)$ and $X_{2}(\theta)$ of the model are very significant, and $X_{3}(l)$ is significant. The interaction term $X_{1} X_{2}$ of the model is not significant, and the effects of $X_{1} X_{3}$ and $X_{2} X_{3}$ are significant. The quadratic terms $X_{1}^{2}$ and $X_{3}^{2}$ of the model have no significant effect, but $X_{2}^{2}$ has a very significant effect. According to the regression coefficient of each factor of the model, the primary and secondary order of the influence of each factor is $X_{1}, X_{3}$ and $X_{2}$, that is, $\alpha, l$ and $\theta$. 
Table 3. Simulation test design and results ${ }^{1}$.

\begin{tabular}{|c|c|c|c|c|c|}
\hline & \multicolumn{5}{|c|}{ Evaluation Indicators } \\
\hline & $X_{1}$ & $X_{2}$ & $X_{3}$ & $Y_{1}$ & $Y_{2}$ \\
\hline Experiment & $\alpha$ & $\theta$ & $l$ & $C D$ (Grain) & $C V(\%)$ \\
\hline 1 & -1 & -1 & 0 & 50 & 21.12 \\
\hline 2 & 1 & -1 & 0 & 23 & 32.36 \\
\hline 3 & -1 & 1 & 0 & 13 & 7.56 \\
\hline 4 & 1 & 1 & 0 & 2 & 23.9 \\
\hline 5 & -1 & 0 & -1 & -2 & 12.13 \\
\hline 6 & 1 & 0 & -1 & -7 & 40.1 \\
\hline 7 & -1 & 0 & 1 & 36 & 12.23 \\
\hline 8 & 1 & 0 & 1 & -5 & 13.7 \\
\hline 9 & 0 & -1 & -1 & 35 & 28.92 \\
\hline 10 & 0 & 1 & -1 & 3 & 11.21 \\
\hline 11 & 0 & -1 & 1 & 26 & 26.65 \\
\hline 12 & 0 & 1 & 1 & 45 & 6.9 \\
\hline 13 & 0 & 0 & 0 & 8 & 10.98 \\
\hline 14 & 0 & 0 & 0 & -5 & 11.23 \\
\hline 15 & 0 & 0 & 0 & -2 & 12.78 \\
\hline 16 & 0 & 0 & 0 & 4 & 4.71 \\
\hline 17 & 0 & 0 & 0 & 4 & 16.18 \\
\hline
\end{tabular}

${ }^{1} X_{1}$-inclination angle of the bottom surface of the conical seed box $(\alpha), X_{2}$-half angle of the top conical of the conical seed box $(\theta), X_{3}$-length parameter range of drainage plate in conical seed box $(l), C D$-the compensation difference (the amount of seed taken minus the amount of seed replenishment), and $C V$ - the coefficient of variation of the average seed-population velocity.

Table 4. Variance analysis of regression models.

\begin{tabular}{|c|c|c|c|c|c|c|c|c|}
\hline \multirow{2}{*}{$\begin{array}{l}\text { Source of } \\
\text { Variance }\end{array}$} & \multicolumn{4}{|c|}{$C D\left(Y_{1}\right) /$ Grain } & \multicolumn{4}{|c|}{$C V\left(Y_{2}\right) / \%$} \\
\hline & $\begin{array}{l}\text { Sum of } \\
\text { Squares }\end{array}$ & $D F^{1}$ & $F$ & $\begin{array}{c}\text { Significance } \\
\text { level } p^{2}\end{array}$ & $\begin{array}{l}\text { Sum of } \\
\text { Squares }\end{array}$ & $D F^{1}$ & $F$ & $\begin{array}{c}\text { Significance } \\
\text { Level } p^{2}\end{array}$ \\
\hline Model & 5202.07 & 9 & 10.76 & $0.0025^{* *}$ & 1441.31 & 9 & 7.56 & $0.0071^{* *}$ \\
\hline$X_{1}$ & 882.00 & 1 & 16.42 & $0.0049^{* *}$ & 406.41 & 1 & 19.18 & $0.0032^{* *}$ \\
\hline$X_{2}$ & 630.13 & 1 & 11.73 & 0.0111 * & 442.23 & 1 & 20.87 & $0.0026^{* *}$ \\
\hline$X_{3}$ & 666.13 & 1 & 12.40 & $0.0097^{* *}$ & 135.14 & 1 & 6.38 & $0.0395 *$ \\
\hline$X_{1} X_{2}$ & 64.00 & 1 & 1.19 & 0.3112 & 6.50 & 1 & 0.31 & 0.5968 \\
\hline$X_{1} X_{3}$ & 324.00 & 1 & 6.03 & $0.0437^{*}$ & 175.56 & 1 & 8.29 & 0.0237 * \\
\hline$X_{2} X_{3}$ & 650.25 & 1 & 12.10 & 0.0103 * & 1.04 & 1 & 0.049 & 0.8310 \\
\hline$X_{1}^{2}$ & 2.53 & 1 & 0.047 & 0.8344 & 131.55 & 1 & 6.21 & $0.0415^{*}$ \\
\hline$X_{2}^{\frac{1}{2}}$ & 1852.42 & 1 & 34.48 & $0.0006^{* *}$ & 84.11 & 1 & 3.97 & 0.0866 \\
\hline$X_{3}^{2}$ & 84.32 & 1 & 1.57 & 0.2505 & 32.41 & 1 & 1.53 & 0.2560 \\
\hline Residual & 376.05 & 7 & & & 148.30 & 7 & & \\
\hline Lack of fit & 267.25 & 3 & 3.28 & 0.1409 & 78.84 & 3 & 1.51 & 0.3401 \\
\hline Pure error & 108.80 & 4 & & & 69.46 & 4 & & \\
\hline Total & 5578.12 & 16 & & & 1589.61 & 16 & & \\
\hline
\end{tabular}

${ }^{1} D F$ - degrees of freedom. ${ }^{2} p<0.01$ is highly significant ${ }^{* *}$, and $p<0.05$ is significant ${ }^{*}$.

Table 4 shows that the regression model of $C V p<0.01$ indicates that the quadraticregression model of $C V$ is very significant. The lack of fit $p>0.05$ and the lack of fit are not significant, indicating that the quadratic-regression equation fitted by the model is consistent with the results of the numerical-simulation test and can correctly reflect the relationship between $Y_{2}$ and $X_{1}$ and $X_{2}$ and $X_{3}$. The regression model can better predict various test results in the optimization test. The primary terms $X_{1}(\alpha)$ and $X_{2}(\theta)$ of the model are very significant, and $X_{3}(l)$ is significant. The interaction Items $X_{1} X_{2}$ and $X_{2} X_{3}$ of the model are not significant, but $X_{1} X_{3}$ has a significant impact. The quadratic term $X_{1}^{2}$ of the model has a significant impact, but $X_{2}^{2}$ and $X_{3}^{2}$ have no significant impact. According to the regression coefficient of each factor in the model, the primary and secondary order of the influence of each factor is $X_{2}, X_{1}$ and $X_{3}$, that is, $\theta, \alpha$ and $l$. 
As shown in Figures 8 and 9, to analyze the relative influence of different levels of interaction of the test factors on each index, according to the quadratic-regression model obtained by analysis, the response surface diagrams of three different interaction levels for $\alpha, \theta$ and $l$ of $C D$ and $C V$ are drawn.

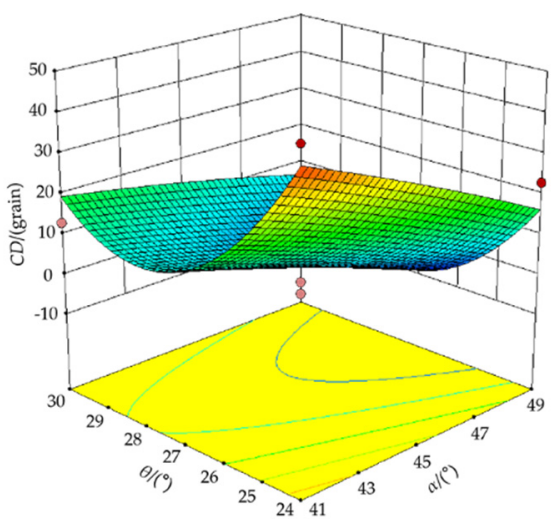

(a)

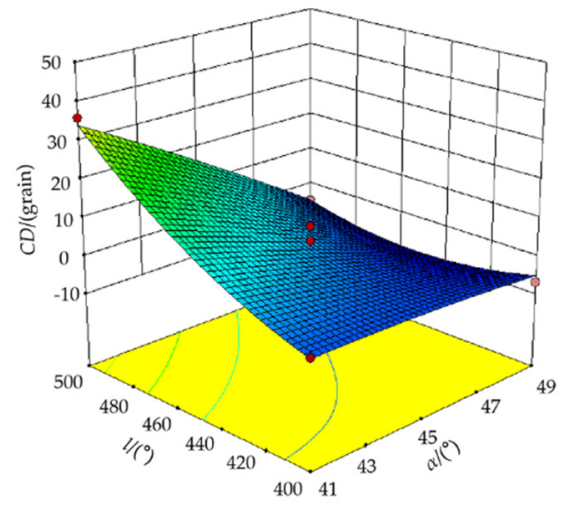

(b)

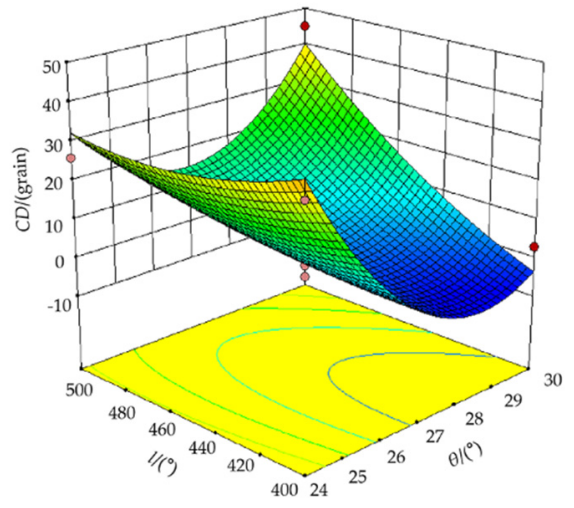

(c)

Figure 8. The influence of the interaction of various factors on $C D$ of evaluation indices: (a) $\alpha$ and $\theta^{\prime} \mathrm{s}$ influence on $C D ;(\mathbf{b}) \alpha$ and $l$ 's influence on $C D ;(\mathbf{c}) \theta$ and $l$ 's influence on $C D$.

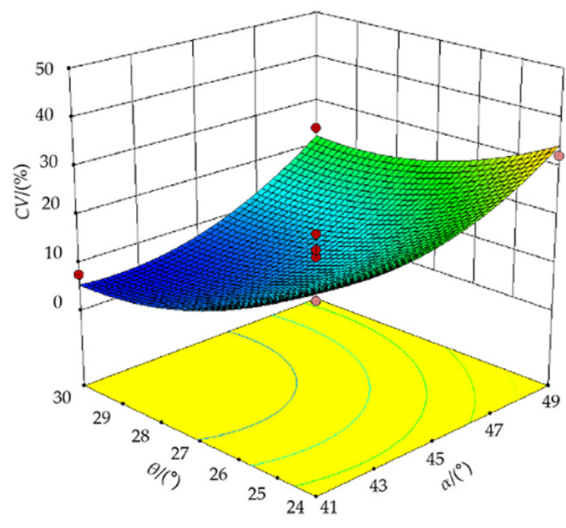

(a)

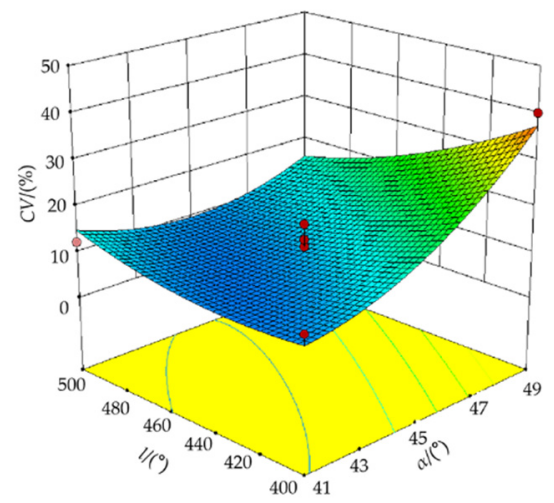

(b)

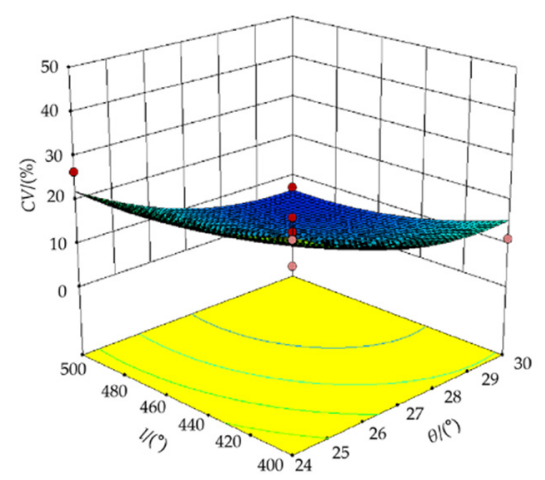

(c)

Figure 9. The influence of the interaction of various factors on $C V$ of evaluation indices: (a) $\alpha$ and $\theta$ influence on $C V ;(\mathbf{b}) \alpha$ and $l$ influence on $C V$; (c) $\theta$ and $l$ influence on $C V$.

As shown in Figure 8a, when $l$ is constant, $C D$ decreases gradually with increasing $\alpha$. With $\theta$ from $24^{\circ}$ to $30^{\circ}, C D$ first decreases and then increases, mainly because, when $\theta$ increases to a certain extent, the flow speed of the seed potato is very slow, and the number of reseeding seeds decreases. Therefore, under the same $l, \theta$ has a great influence on $C D$. As shown in Figure $8 \mathbf{b}$, when $\theta$ is fixed, the absolute value of $C D$ increases slowly with increasing $\alpha$. With increasing $l$ from $400 \mathrm{~mm}$ to $500 \mathrm{~mm}$, the absolute value of $C D$ decreases first and then increases. Therefore, when $\theta$ is fixed, $l$ has a great influence on $C D$. As shown in Figure $8 \mathrm{c}$, when $\alpha$ is constant, as $\theta$ increases from $24^{\circ}$ to $30^{\circ}$, the absolute value of $C D$ decreases sharply first and then increases; with an increase in $l$, the change in $C D$ is not obvious. Therefore, when $\alpha$ is certain, $\theta$ has a great influence on $C D . \alpha, l$ and $\theta$ on $C D$ and $\mathrm{CV}$ are drawn, respectively.

As shown in Figure 9, the degree of influence of each factor interaction on $C V$ is shown. As shown in Figure 9a, when $l$ is constant, $C V$ gradually increases to the maximum with an increase in $\alpha$; with an increase in $\theta, C V$ gradually decreases to the minimum. Therefore, when $l$ is constant, the two factors have a significant effect on $C V$. As shown in 
Figure $9 \mathrm{~b}$, when $\theta$ is fixed, $C V$ gradually increases to the maximum with an increase in $\alpha$ from $41^{\circ}$ to $49^{\circ}$; with an increase in $l, C V$ also increases gradually, but the influence on $\alpha$ is not significant. As shown in Figure $9 c$, when $\alpha$ is constant, $C V$ gradually decreases with increasing $\theta ; l$ has no significant effect on $C V$.

To ensure the seed-metering performance of the conical seed box, the structural parameters of the seed box were optimized with the optimization objectives of low $C D\left(Y_{1}\right)$ and low $C D\left(Y_{2}\right)$. Design-Expert V8.0.6 was used to optimize the numerical module in the data-analysis software. The objective function and constraint conditions are Formula (8).

$$
\left\{\begin{array}{l}
\min _{1} Y_{1} \\
\min Y_{2} \\
X_{1} \in[-1,1] \\
X_{2} \in[-1,1] \\
X_{3} \in[-1,1]
\end{array}\right.
$$

The interactive terms $X_{1} X_{2}$ and quadratic terms $X_{1}^{2}$ and $X_{3}^{2}$ that had no significant impact on the $Y_{1}$ model were removed. The interactive terms $X_{1} X_{2}$ and $X_{2} X_{3}$ and the quadratic terms $X_{2}^{2}$ and $X_{3}^{2}$ that had no significant impact on the $Y_{2}$ model were eliminated. Through the Design-Expert V8.0.6 software, the best parameter combination was selected as follows: $\alpha$ was $41.40^{\circ}, \theta$ was $29.55^{\circ}, l$ was $400.50 \mathrm{~mm}$, the $C D$ predicted by the model was -7 grains, and $C V$ was $4.69 \%$.

Taking Experiments 6 and 10 in the factor-level test as examples, the simulation results for the force state and motion state of the seed potatoes under general structural parameters and optimal structural parameters were compared. In Experiment 6, Experiment 10 and the seed box with the optimal structural parameters (Figure 10), $Q$ was $0.141 \mathrm{~N}, 0.061 \mathrm{~N}$ and $0.082 \mathrm{~N}$, respectively, and the standard deviations of $Q$ were $0.076,0.066$ and 0.044 , respectively (Figure 10a). The average values of the flow velocity of the seed-potato population were $0.068 \mathrm{~m} / \mathrm{s}, 0.015 \mathrm{~m} / \mathrm{s}$ and $0.042 \mathrm{~m} / \mathrm{s}$, respectively, and the standard deviations of the velocity were $0.027,0.017$ and 0.009 , respectively (Figure 10b). In Experiment 6, the seed potato was greatly affected by autogenous gravity. According to the standard deviation of $Q$ and velocity of the potato group, the movement of the seed-potato group was very unstable. Moreover, the fast flow speed of the seed-potato group caused more seed potatoes to accumulate in the seed-metering area, and the seed-metering device easily caused damage to the seed potato in the seed-metering process. In Experiment 10, $Q$ was small, so the movement speed of the potato group was small. Due to the extrusion of upper seed tubers, the friction between seed tubers in the reseeding area increases, and the seed tubers form an arching phenomenon in the reseeding area (Table 5). For the single side arch of seed potatoes, the potato group did not flow as a whole, and the seed missing rate for the seed-metering device on the right increased. The average value of the flow velocity of the potato group in the seed box with the best parameters was $0.042 \mathrm{~m} / \mathrm{s}$. Based on the above analysis and test indicators, combined with the known operating speed of the seed-taking device of $0.6 \mathrm{~m} / \mathrm{s}$, the movement speed of the potato group in the seed box with the best structural parameters was reasonable. In the seed box with the best structural parameters (Table 5), the seed-potato group showed an overall flow, and there was no arching phenomenon. 


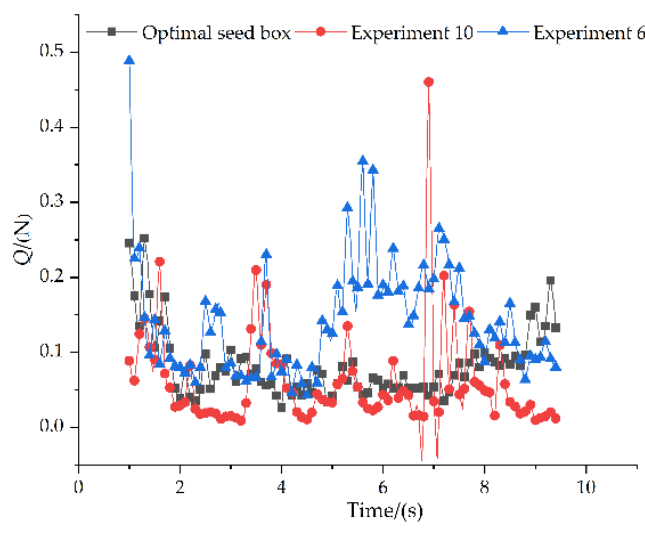

(a)

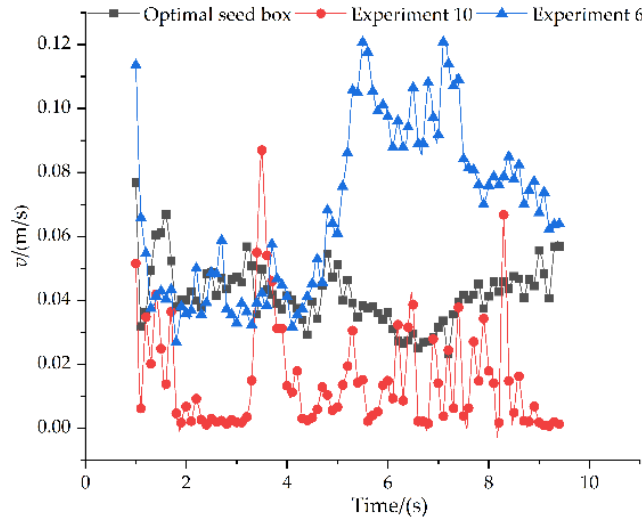

(b)

Figure 10. Comparison of seed-potato states in conical seed box with general structural parameters and optimal structural parameters: (a) Comparison of stress states of seed potato and (b) comparison of movement speeds of seed potatoes.

Table 5. Motion states of seed potatoes in a conical seed box with general structural parameters and a conical seed box with optimal structural parameters at different simulation times.

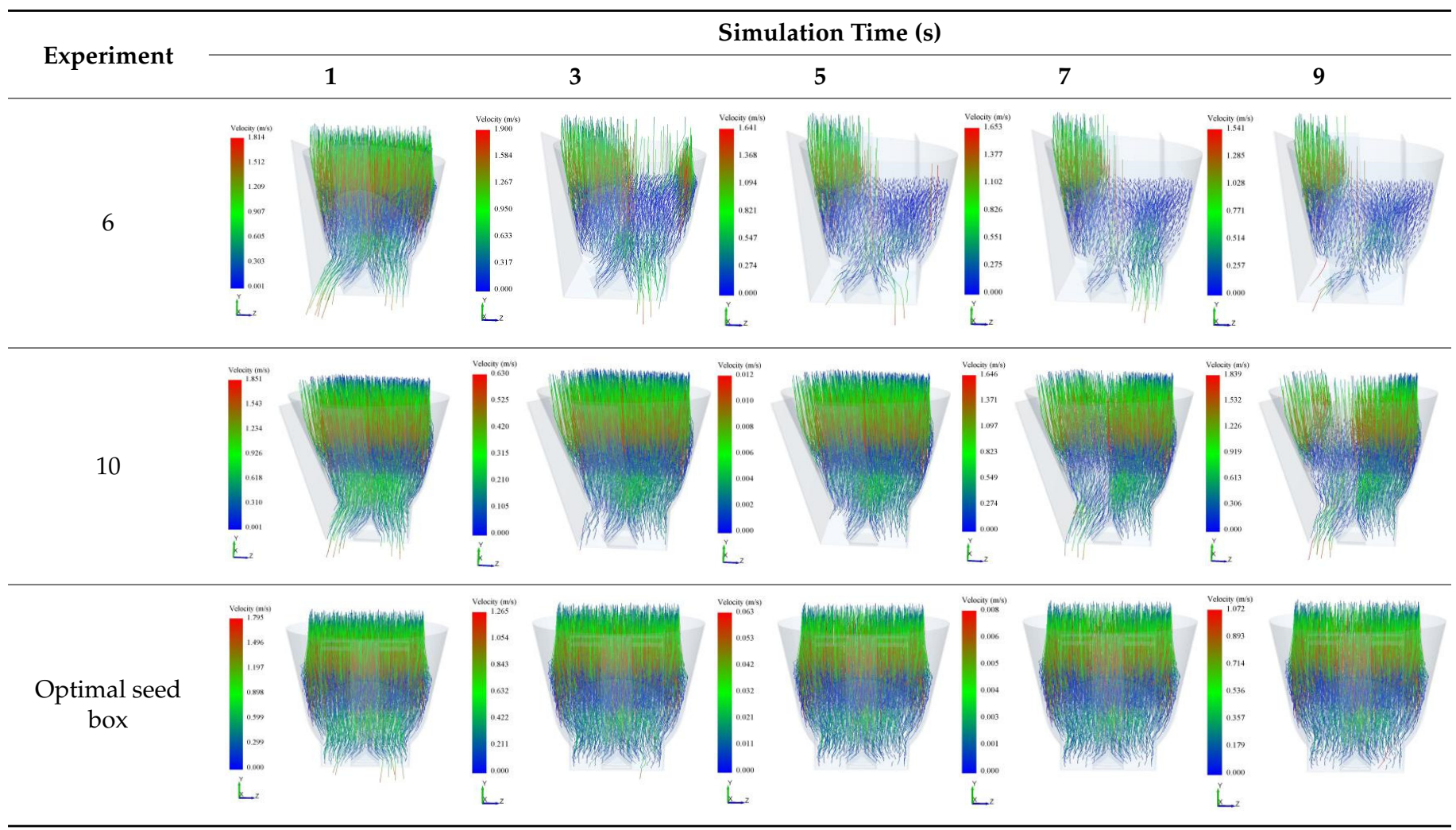

\section{Bench-Verification Test and Discussion}

To verify the accuracy of the optimization results, in December 2021, according to the optimal structural parameters obtained from the simulation optimization results $\left(\alpha\right.$ is $41.40^{\circ}$, $\theta$ is $29.55^{\circ}$ and $l$ is $400.50 \mathrm{~mm}$ ), the conical seed box was trial-manufactured and installed on the seed-metering device of the cup-belt potato planter, and the bench-verification test was carried out in the laboratory of the School of Mechanical and Electrical Engineering, Shihezi University, Xinjiang (Figure 11). 


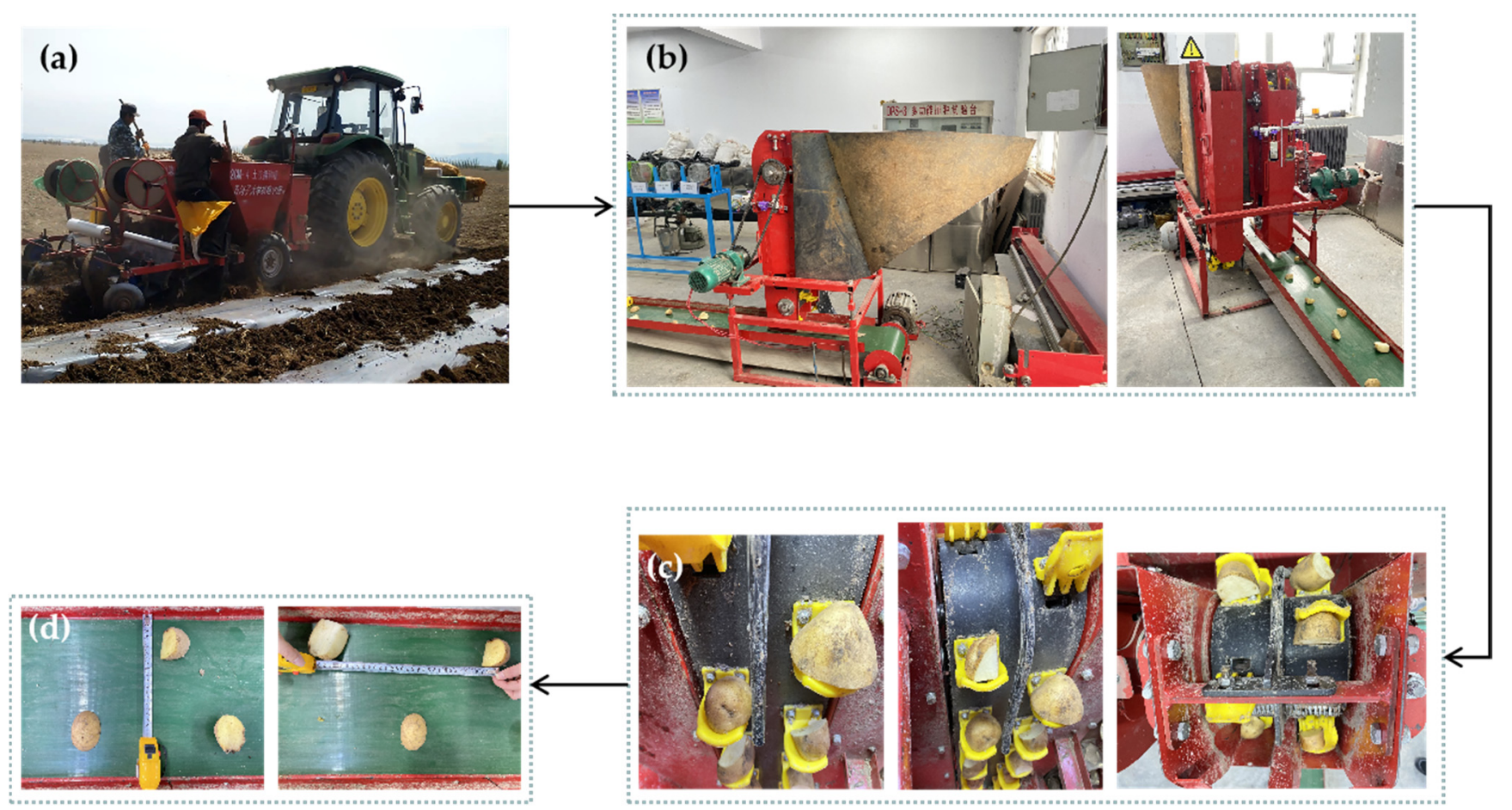

Figure 11. Bench-verification test of the new cup-belt potato planters: (a) When the potato planter equipped with cross-angle seed box works in the field, it needs to break the arching phenomenon manually; (b) When the seed potato was tested in the newly designed conical seed box, the flow was stable; (c) Observation and statistical test evaluation index: Multiples Rate (\%); Missing Rate (\%); (d) Measurement and calculation of test evaluation index:Coefficient of Variation of Plant Distance (\%).

The potato variety "Xin Daping" was selected in the experiment. The seed potato was obtained from $85 \mathrm{~g}$ of whole potato after two longitudinal petals, and the weight was approximately $40 \mathrm{~g}$. The speed of the seed-metering device was established as $0.6 \mathrm{~m} / \mathrm{s}$ with reference to the field-operation speed. The diameter of the seed cup was $60 \mathrm{~mm}$, and the seed-throwing height was $12 \mathrm{~mm}$. The technical requirements of the GB/T 6242-2006 test and Method for Planting Machinery Potato Planting Machines were referenced, and the multiple rate, missing rate, and coefficient of the variation of the plant distance were used as evaluation indices.

$$
\left\{\begin{array}{l}
D=\frac{n_{1}}{N} \times 100 \% \\
M=\frac{n_{2}}{N} \times 100 \% \\
C V_{\mathrm{d}}=\sigma \times 100 \%
\end{array}\right.
$$

where

$D$ —the multiple rate (\%);

$M$-the missing rate (\%);

$C V_{\mathrm{d}}$-the coefficient of the variation of the plant distance (\%);

$\sigma$-the standard deviation;

$N$-the theoretical number of seeds metered (grain);

$n_{1}$ - the number of repeated seeds (grain);

$n_{2}$ - the number of missed seeds (grain).

To eliminate random errors, five repeatability tests were conducted to take the average value, and 200 seed meters were completed in each test. The test results are shown in Table 6. The results show that the average test values of the multiple rate, missing rate, and coefficient of the variation of the plant distance were $5.35 \%, 2.48 \%$ and $10.43 \%$, respectively. At the same time, the test results for the intersection-angle seed box and conical seed box are compared, as shown in Table 7 . The results show that the multiple rate, missing rate and coefficient of the variation of the plant distance of the conical seed box were 
reduced by $4.76 \%, 4.0 \%$ and $9.18 \%$, respectively [37]. The experimental results show that the seed-metering performance of the conical seed box was better than the seed-metering performance of the intersection-angle seed box. At the same time, there was a good effect on improving the sowing performance of the planter, and the rationality of the structural design of the conical seed box was verified.

Table 6. Results of the seed-metering-performance verification test of the conical seed box.

\begin{tabular}{cccc}
\hline Test No. & Multiple Rate (\%) & Missing Rate (\%) & $\mathbf{C V}_{\mathbf{d}} \mathbf{1} \mathbf{( \% )}$ \\
\hline 1 & 5.42 & 2.34 & 9.74 \\
2 & 6.11 & 2.71 & 10.48 \\
3 & 5.09 & 2.91 & 11.61 \\
4 & 4.74 & 1.93 & 9.27 \\
5 & 5.37 & 2.51 & 11.05 \\
Average value & 5.346 & 2.48 & 10.43 \\
\hline
\end{tabular}

${ }^{1} \mathrm{C} V_{\mathrm{d}}$ - coefficient of variation of plant distance.

Table 7. Test results for the intersection-angle seed box and conical seed box.

\begin{tabular}{cccc}
\hline Test Index & $\begin{array}{c}\text { Chinese National } \\
\text { Standards }\end{array}$ & $\begin{array}{c}\text { Intersection-Angle } \\
\text { Seed Box }\end{array}$ & Conical Seed Box \\
\hline Multiple Rate $(\%)$ & $\leq 20 \%$ & $10.11 \%$ & $5.35 \%$ \\
Missing Rate $(\%)$ & $\leq 13 \%$ & $6.48 \%$ & $2.48 \%$ \\
$C V_{\mathrm{d}}{ }^{(}(\%)$ & $\leq 33 \%$ & $19.61 \%$ & $10.43 \%$ \\
\hline
\end{tabular}

${ }^{1} \mathrm{C} V_{\mathrm{d}}$-coefficient of variation of plant distance.

\section{Conclusions}

(1) In this study, from the analysis of the arching phenomenon of the seed potato in the intersection-angle seed box, a digital twin of the planter was created for the first time, and a conical-shaped seed box was designed. By analyzing the motion state of seed potatoes in the conical seed box, the mechanical equations of the friction resistance between seed-potato particles and the force acting on the downward flow of the seed potatoes were established.

(2) The structural parameters of the conical seed box were analyzed. The main structural parameters affecting the seed-metering performance of the seed box were obtained. At the same time, there was no seed-isolation baffle, and there was no seed-metering box or reseeding box, which reduced the intersection angle of the seed box, to avoid the arching phenomenon of the seed potato caused by poor flow conditions at the intersection angle of the seed potato in the seed-reseeding box. Compared with the intersection-angle seed box, the multiple rate, missing rate and coefficient of the variation of the plant distance of the conical seed box were reduced by $4.76 \%, 4.0 \%$ and $9.18 \%$, respectively. Finally, the missing rate was reduced, and the sowing performance of the cup-belt potato planters was improved.

(3) In the research, only the flow performance of the seed box was considered, but there are many factors affecting the missing sowing of the planter, such as the working performance of the seed-cup-belt metering device and the vibration frequency of the planter in the field. Therefore, in future research, multiple factors should be systematically considered to ensure the objectivity of the research and provide a reference for research on improving the operational performance of cup-belt potato planters. In addition, this study also has reference significance for the study of the arching phenomenon of granular materials in boxes.

The purpose of this study was to solve the problem of missed sowing caused by the arching phenomenon of the seed box of potato planters, and the ultimate purpose was to improve the sowing performance of potato planters. At the same time, this study has referential significance for the study of the arching phenomenon of granular materials in the box. 


\begin{abstract}
Author Contributions: Conceptualization, H.C., B.H. and Z.M.; methodology, H.C., Y.C., X.L. and J.W.; software, H.C., J.W. and C.Y.; validation, H.C., J.W., Z.M. and C.Y.; formal analysis, H.C., B.H., Y.C. and J.W.; investigation, H.C., J.W., Z.M. and C.Y.; resources, B.H. and Y.C.; data curation, H.C., J.W. and C.Y.; writing-original draft preparation, H.C., J.W., Z.M. and C.Y.; writing-review and editing, H.C.; visualization, H.C.; supervision B.H. and Y.C.; project administration, X.L., J.W., Z.M and C.Y.; funding acquisition, B.H., X.L. and Y.C. All authors have read and agreed to the published version of the manuscript.
\end{abstract}

Funding: The research was supported by the National Natural Science Foundation of China (No. 52165036), National Natural Science Foundation of China (No. 51665050) and Key Laboratory of Modern Agricultural Machinery Corps Open Project in 2021 (No. BTNJ2021001).

Institutional Review Board Statement: Not applicable.

Informed Consent Statement: Not applicable.

Data Availability Statement: All the relevant data presented in the article are stored according to institutional requirements and, as such, are not available online. However, all the data used in this manuscript can be made available upon request to the authors.

Conflicts of Interest: The authors declare no conflict of interest.

\title{
References
}

1. Huang, J.Y. Design of the fertilizing and seeding module of the small multifunctional agricultural machinery. Mod. Mach. 2016, 3, 5-11.

2. Song, Y.P. Key Components Design of Potato Micro Seed Planter. Trans. Chin. Soc. Agric. Eng. 2018, 8, 3-14.

3. Hu, J.P.; Guo, K.Z.; Chun, J.; Hou, C. Simulation and Experiment of Supplying Seeds in Box of Magnetic Precision Cylinder-seeder. Trans. Chin. Soc. Agric. Mech. 2014, 45, 61-65. [CrossRef]

4. Niu, K.; Yuan, Y.; Luo, M.; Liu, Y.C.; Lv, C.X.; Fang, X.F. Design and experiment of potato metering device with double-deck seed tank. Trans. Chin. Soc. Agric. Mech. 2016, 32, 8-19. [CrossRef]

5. Li, X.M.; Zhang, Z.L.; Wang, J.L. Roller Pneumatic Tray Seeding Machine Box Structure Design and Experimental Study. J. Agric. Mech. Res. 2012, 9, 5-9. [CrossRef]

6. Chen, H.B. Rational Design of Solid Silo. Chem. Eq. Technol. 1995, 16, 4-7.

7. Wang, L.W. Summary of arch-building mechanism and arch-breaking ways of materials in hopper. Foundry Equip. Technol. 1982, 4, 70-79.

8. Jenike, A.W. Quantitative design of mass-flow bins. Powder Technol. 1967, 1, 237-244. [CrossRef]

9. Ban, H.; Roh, S.; Park, W.J. Performance Evaluation of Buried Concrete Pipe Considering Soil Pressure and Crack Propagation Using 3D Finite Element Analysis. Appl. Sci. 2021, 11, 3292. [CrossRef]

10. Zhang, H.; Liu, M.; Zhou, P.; Zhao, Z.; Li, X.; Xu, X.; Song, X. Analysis of Earth Pressure Variation for Partial Displacement of Retaining Wall. Appl. Sci. 2021, 11, 4152. [CrossRef]

11. Ma, Z.R.; Gao, L.; Zhong, Y.L.; Ma, S.; An, B.L. Arching Detection Method of Slab Track in High-Speed Railway Based on Track Geometry Data. Appl. Sci. 2020, 10, 6799. [CrossRef]

12. Nikiitenko, A.V. Mathematical simulation of the arch formation process of the loose protecting filtering material in the load box of the drainage machine bunker. Prirodoobustroistvo 2010, 1, 89-93.

13. CEN. Design of Steel Structures: Part 1-6. General Rules-Supplementary Rules for the Shell Structures; CEN: Brussels, Belgium, 2002 ; p. 83.

14. Izmaylov, A.Y.; Kolchin, N.N.; Lobachevskiy, Y.P.; Kynev, N.G. Modern technologies and special equipment for potato production Following materials of the Potato Europe 2014 exhibition part 1. Сельскохозяйственные Машины И Технологии 2015, 2. [CrossRef]

15. Tekeste, M.Z.; Mousaviraad, M.; Rosentrater, K.A. Discrete Element Model Calibration Using Multi-Responses and Simulation of Corn Flow in a Commercial Grain Auger. Trans. ASABE 2018, 61, 1743-1755. [CrossRef]

16. Zhou, M.; Hua, Z.; Wang, J.; Lei, W.; Yin, D. New type of transverse moving box mechanism for pot seedling transplanting machine. Int. J. Agric. Biol. Eng. 2018, 11, 70-75. [CrossRef]

17. Hu, H.; Li, H.; Wang, Q.; He, J.; Liu, P. Anti-blocking performance of ultrahigh-pressure waterjet assisted furrow opener for no-till seeder. Int. J. Agric. Biol. Eng. 2020, 13, 64-70. [CrossRef]

18. Yang, P.; Li, L.; Aubertin, M. Theoretical and Numerical Analyses of Earth Pressure Coefficient along the Centerline of Vertical Openings with Granular Fills. Appl. Sci. 2018, 8, 1721. [CrossRef]

19. Yan, C.L. The development of wood particulate to bridge over openings abroad. Fores. Grass. Mach. $2014,25,56-57$.

20. Lv, J.Q.; Yang, X.H.; Li, Z.H.; Li, J.C.; Liu, Z.Y. Design and Test of Seed Potato Cutting Device with Vertical and Horizontal Knife Group. Trans. Chin. Soc. Agric. Mech. 2020, 51, 89-97. [CrossRef]

21. Liu, J.Y. Phenomenon analysis and elimination means of bulk material bridging in storage daybin. Chin. Rubb. Tech. Equip. 2016, 21, 4-11.

22. Zhao, X.; Huang, Y.; Chen, S.; Li, J. Study and Test of Potato Planter with Filming and Piping Device. J. Agric. Mechan. Res. 2018, 40, 124-129. 
23. Ketterhagen, W.R.; Curtis, J.S.; Wassgren, C.R.; Hancock, B.C. Predicting the flow mode from hoppers using the discrete element method. Powder Technol. 2009, 195, 1-10. [CrossRef]

24. Jenike, A.W. Gravity Flow of Bulk Solids; Bulletin No. 108; Utah State University: Salt Lake, UT, USA, 1961.

25. Deng, W.J.; Li, Z.W.; Qiu, X.L.; Wang, W.; Wu, X.; Zheng, D.K. The Research of Rice Liquidity and Arching Based on Crossed Diversion Seed-box. J. Agric. Mechan. Res. 2013, 12, 145-149.

26. Lv, J.Q.; Yu, J.Y.; Feng, X.; Li, Z.H.; Yang, X.H.; Xin, Y.W. Analysis of physical characteristics of potato seed potato. In Proceedings of the Potato Industry and Healthy Consumption, Enshi, China, 25-28 May 2019.

27. Kawakami, T.; Oohori, H.; Tajima, K. Seed potato production system in Japan starting from foundation seed of potato. Breed. Sci. 2015, 65, 17-25. [CrossRef]

28. Akita, M.; Ohta, Y. A simple method for mass propagation of potato (Solanum tuberosum L.) using a bioreactor without forced aeration. Plant. Cell. Rep. 1998, 18, 284-287. [CrossRef]

29. Shi, L.; Sun, W.; Zhao, W. Parameter determination and validation of discrete element model of seed potato mechanical seeding Trans. Chin. Soc. Agric. Eng. 2018, 34, 35-42. [CrossRef]

30. Feng, B.; Sun, W.; Shi, L. Determination of restitution coefficient of potato tubers collision in harvest and analysis of its influence factors. Chin. Soc. Agric. Eng. 2017, 13, 58-65. [CrossRef]

31. Lobo-Guerrero, S.; Vallejo, L.E. Fibre-reinforcement of granular materials: DEM visualisation and analysis. Geomech. Geoengin. 2010, 5, 79-89. [CrossRef]

32. Bourrier, F.; Kneib, F.; Chareyre, B.; Fourcaud, T. Discrete modeling of granular soils reinforcement by plant roots. Ecol. Eng. 2013, 61, 646-657. [CrossRef]

33. Norman-Ham, H.A.; Hanna, M.H.; Richard, T.L. Solid Manure Distribution by Rear- and Side-Delivery Spreaders. Trans. ASABE 2008, 51, 831-843. [CrossRef]

34. Jiang, H.Y.; Zhou, M.C.; Li, H.R.; Jiang, Z.H. Experiment on Dynamic Droplet Distribution Uniformity for PWM Variable Spray System. Trans. Chin. Soc. Agric. Mach. 2015, 46. [CrossRef]

35. Zhang, J.X.; Rui, Z.Y.; Cai, J.L.; Wang, Y.C.; Yeerbolati, T.; Gao, Z.M. Design and Test of Front Mounted Belt Clamping and Conveying Cotton-stalk Pulling Device. Trans. Chin. Soc. Agric. Mach. 2017, 13, 1-9.

36. Solhi, L.; Sun, H.S.; Daswani, S.H.; Shojania, S.; Springate, C.M.; Brumer, H. Controlled sulfation of mixed-linkage glucan by Response Surface Methodology for the development of biologically applicable polysaccharides. Carbohydr. Polym. 2021, 269, 118275. [CrossRef]

37. Zhao, X.X. Design and Seed Metering Performance of Potato Seed Metering Device; Shihezi University: Xinjiang, China, 2017. 